\title{
Resiliency characteristics of a competitive and collaborative complex adaptive supply network
}

\author{
Selen Onel, Abe Zeid and Sagar Kamarthi* \\ Department of Mechanical and Industrial Engineering, \\ Northeastern University, \\ 360 Huntington Ave., \\ 330 Snell Engineering, \\ Boston, Massachusetts 02115, USA \\ Email: selenonel@gmail.com \\ Email: zeid@coe.neu.edu \\ Email: sagar@coe.neu.edu \\ ${ }^{*}$ Corresponding author
}

\begin{abstract}
This paper investigates the topological and dynamic characteristics of computer manufacturing enterprises needing to operate competitively in a rapidly changing business environment. It studies the evolution of topological structures of the computer manufacturing enterprise ecosystem (CMEE) from a complex adaptive systems (CASs) theory perspective. An agent-based model is built based on the self-organisation and adaptation concepts borrowed from biological ecosystems and agility and alignment concepts from manufacturing systems. It studies the end effect of decisions and actions of enterprise managers and changing trends in the computer manufacturing environment. The results of this research indicate that enterprises, which adjust their goals and infrastructure quickly in response to changes in customer expectations, supplier capabilities, and/or intentions of competitors, survive longer in the CMEE compared to the enterprises that resist change. Surprisingly, the suppliers that deliberately resist changes survive better than the ones that stay neutral to change. Furthermore, enterprises which adopt a cooperative behaviour excel over their greedy competitors.
\end{abstract}

Keywords: agent-based simulation; CASs; complex adaptive systems; competitive markets; supply chains; collaborative enterprises; resiliency.

Reference to this paper should be made as follows: Onel, S., Zeid, A. and Kamarthi, S. (2015) 'Resiliency characteristics of a competitive and collaborative complex adaptive supply network', Int. J. Collaborative Enterprise, Vol. 5, Nos. 1/2, pp.1-18.

Biographical notes: Selen Onel is a Research Scientist in Kalibrate Technologies, a software company that helps retailers fine-tune pricing and retail location decisions to deliver on performance goals. Her research interests lie in high level predictive and explanatory statistical data analysis, intelligent systems, network theory, optimisation and simulation modelling. Her previous work experience includes Post-doctorate Associate position in Northeastern University (NU) and teaching and research assistant roles. She received her $\mathrm{PhD}$ in Industrial Engineering from NU, May 2012. She received two master degrees one in Computer Systems Engineering and the second in Operations Research from NU. 
Abe Zeid is a Professor of Mechanical and Industrial Engineering at Northeastern University. His research interests include database and information systems in manufacturing, the use of mobile agents to facilitate information access in manufacturing environments. Currently, his research is focused on scalable nanomanufacturing and engineering education. He has published over 200 papers and secured research grants over 3 millions.

Sagar Kamarthi is an Associate Professor of Mechanical and Industrial Engineering at Northeastern University. His research interests are in the areas of machine learning, process monitoring and diagnosis, advanced manufacturing, and nanomanufacturing. He has published more than 170 papers in internationally reputed journal and has secured several grants, totalling over 3 million, from the National Science Foundation.

\section{Introduction}

Today business markets are highly non-linear, fast evolving and emerging. Crucial elements of this dynamic environment include supply chains with innumerable interactions and inter-dependencies, evolving global and local economies, and increasing customer expectations. Faced with high complexity and unpredictable changes, enterprises look for different approaches to make their supply chains agile. They adopt different strategies to anticipate and quickly adapt to forthcoming changes (Robinson and Satterfield, 1998; Krause et al., 2000; Mahajan et al., 2002; Robinson et al., 2005; Qi et al., 2009, 2011; Heese, 2012). They want to timely diagnose system deficiencies such as lack of dynamism, absence of control, and weak network. Further they want to predict forthcoming future trends and organise their respective systems accordingly.

The success of enterprises require adaptive capabilities, working business relationships, strong information flow, and collaboration links with their suppliers, customers and surprisingly even with their current and potential competitors. Many enterprises have spent increasing amounts of time, money, and resources to predict system changes and control system behaviour. However, predicting the exact future is impossible when changes are perennial and come in different forms.

This research takes a unique approach. It studies the influence and effect of decisions and actions of enterprises in a dynamic, rapidly changing and uncertain ecosystem. The study uses concepts and tools from complex adaptive systems (CASs) and agent-based modelling methods to study the evolution of topological structures that form the computer manufacturing enterprise ecosystem (CMEE). An agent-based model is built on the self-organisation and adaptation concepts borrowed from biological ecosystems (Ito and Gunji, 1994; Sneppen et al., 1995; Pascual et al., 2002) and the reconfigurability, agility and alignment concepts from manufacturing systems (Koren et al., 1999; Zhang et al., 2002; Setchi and Lagos, 2004; Su and Chen, 2004; Tang and Qiu, 2004; Wang et al., 2005; ElMaraghy, 2006). This approach affords us to model and analyse a realistic CMEE to gain insights into the characteristics of enterprises that ought to be highly dynamic, scalable, reconfigurable, agile and adaptive.

In this research, we investigate agility, alignment and adaptivity measures, the key components of a triple-A supply chain (Lee, 2004), to understand the necessary survival skills in the business ecosystem. 
The first measure studied in this work is agility. It is the ability of an enterprise to rapidly and efficiently respond to changes. Agility refers to timely response to changes in short term. It requires rapid decision making and execution and being nimble to new market and technological trends. Nearly $90 \%$ of executives surveyed by the Economist Intelligence Unit believe that organisational agility is critical to business success (Economist, 2009).

The second measure of interest is alignment of member companies in the enterprises. Alignment refers to the synchronisation of shared goals and objectives of a set of companies in an ecosystem. The absence of alignment may shrink sales and profits, swell missed delivery dates, promote unmatched priorities, and therefore create chaos in the system. It is not enough to set clear, realistic goals and share them across the enterprise. Complex market structures require concrete strategies and effective communication channels to achieve alignment goals and bring value to the enterprise. Alignment of companies in the enterprise ecosystem has many benefits such as increased sales, higher profits, lower costs, lower turnovers, satisfied employees and better customer service.

The third measure is adaptation, which in biology is defined as the evolutionary process, which takes place over many generations, whereby a population becomes better suited to its habitat. An enterprise ecosystem is a complex system, whose dynamism necessitates constant adaptation. In this ecosystem, emergence of new and non-traditional competitors and increasing customer demands unsettle the current position of companies in the market. Companies, which are not adaptive, would not be able to respond to long range marketplace shifts. The key factors for sustainability and competitiveness are being responsive, being alert and flexible enough to adapt new technologies and ideas in long run. The enterprises which neglect the change become irresponsive and would not be able to use the opportunities that come into play in business. Normally enterprises embrace change to keep moving forward and to keep the company's competitive edge.

The agent-based simulation model incorporates triple-A characteristics (Lee, 2004) into supplier agents. Each agent uses different algorithms and rules to exhibit intelligent behaviour and optimise its choices. The simulation model is analysed using wellestablished methods (Pritsker and Pegden, 1984; Kelton et al., 1998; Law, 2006).

\section{Literature review}

In previous studies, researchers had studied supply chains using equation-based approaches, traditional simulation based approaches, or a combination of both. These modelling approaches are limited to capture the dynamics of today's complex adaptive supply chain systems. Yet the interest in reflecting complexity and dynamism of enterprise systems and supply chains is rapidly growing.

Barlas and Gunduz (2011) investigated the structural sources of the bullwhip effect on complex supply network structures by using a system dynamics simulation. Nair et al. (2009) examined how the firms embedded in supply networks make decisions over time. They built a simulation model using cellular automata to investigate the dynamic evolution and defection among complex adaptive supply network agents. Kaihara (2003) proposed a supply chain management (SCM) based on market-oriented programming that predicts multi-agent behaviour. Monteiro et al. (2010) studied an enterprise network problem to search complementary resources in order to deal with unexpected orders different from the planned forecasting using agent-based simulation approach. Wang 
et al. (2011) developed an ontology-based knowledge representation scheme and two agent interaction protocols for modelling enterprise interactions in a supply chain network via a multi-agent simulation approach. Nair and Vidal (2011) examined the relationship between supply network's topology and its robustness in the presence of random failures and targeted attacks. Amini et al. (2012) studied the impact of alternative production-sales policies on the diffusion of a new generic product and the generated net present value of profit using an agent-based modelling and simulation methodology.

There is a dearth of research that explains the processes that may govern the emergence, growth, and evolution of enterprise system topologies over time (Harland et al., 2001). Kim (2009) modelled a supply network as a CAS, in which firms or agents interact with one another and adapt themselves. He used an agent-based social simulation model, a research method of simulating social systems under the CAS paradigm, to observe emergent outcomes. Just as Kim (2009), many scientists recognised supply networks as CASs. Pathak et al. (2009) investigated the dynamics of a complex adaptive supply network, to understand the stability of the structural evolution of a supply network and supplier population emergence. Their analysis revealed that the type of environment, in which a supply network evolves, appears to be a major factor in determining critical timing of structural changes during the evolution of a complex adaptive supply network. Li et al. (2009) conducted a multi-agent simulation study on the evolution of complex adaptive supply network, and reported that the supply network emerges and evolves from the firms' dynamic interaction under the dynamic environment. Zhang et al. (2010) used an agent-based model to investigate the effects of switch cost and distributors' ordering policy on the evolution of supply network configuration. Baldwin et al. (2010) employed the complex systems thinking in the area of operations and production management. Mizgier et al. (2012) introduced an agent-based model of a supply chain network which represents a real economic environment in which firms operate. Choi and Hong (2002) reported that from a policy maker/strategist's point-of-view, the impact of the dynamic forces on the growth and evolution structure of networks is interesting and challenging.

Lee (2004) proposed that a good supply chain needs to have agility, alignment and adaptation properties. He refers to such a supply chain as a triple-A supply chain. The concept of triple-A supply chain offers versatility and flexibility to promote success in business market. There are several scientists who emphasise the importance of adaptivity, flexibility, alignment, collaboration mechanisms and interactions in a supply chain.

Datta and Christopher (2011) investigated the effectiveness of information sharing and coordination mechanisms in reducing uncertainties originating from unexpectedly large demand spikes in a supply chain using an agent-based simulation approach. Chan and Chan (2010) stated that supply chains need to be flexible and adaptive because their operations are always subject to a variety of uncertainties like customer demand and supplier capacity. Jiang et al. (2010) proposed a paradigm for a mobile service chain's competitive and collaborative mechanism using a multi-agent system approach.

We postulate in this paper that in order to better understand a CMEE, it should be considered and modelled as a complex adaptive system (CAS). The novel ideas presented in this paper for modelling and analysis of CMEE extend the concepts, tools and techniques used for studying CASs. We simulate the CMEE using an agent-based model and re-formulated the computer manufacture enterprises as agents, computer manufacture enterprise market as the environment. Additionally, we provide insights into the behaviour of enterprises that ought to be highly dynamic, scalable, aligned, agile and 
adaptive. We outline and discuss triple-A measures and their impact on complex and dynamic CMEE environment.

\section{Multi-agent simulation framework}

Dynamics of any ecosystem become complicated due to the presence of multiple factors and complex interactions. The variations in each component require a better knowledge of the structure and dynamics of the ecosystem. Multi-agent framework of CMEE allows observation of the dynamics of CMEE such as decision making process, information flow, collaboration, and network structure. Multi-agency provides the ability to observe the variations in each component in this ecosystem such as materials flow, distribution, inventory control, information exchange, supplier reliability, number of suppliers, demand forecast mechanisms, and flexibility to change commitments.

\subsection{Agent-based simulation model of CMEE}

In this research we developed an agent-based simulation model using the special purpose simulation modelling environment, NetLogo (Wilensky, 1999), to understand the dynamics of CMEE. The enterprises are constructed using groups of condition-action rules to be able to 'perceive' and 'react' to changes in their environment, to pursue their goals, and to interact with other enterprises, for example, by selling and buying goods via supply-demand links.

\subsection{Agents of CMEE and their properties}

An agent-based model consists of a number of software objects, called agents, interacting within a virtual environment (Terano et al., 2005). In the simulation model, computer manufacturing enterprises (CMEs), their suppliers and customers correspond to agents communicating in the virtual CMEE. Each agent has a degree of autonomy and has goals that it aims to achieve. It also reacts to and acts on CMEE and other agents residing in CMEE. Each agent specialises according to its intended role in the CMEE.

There are two main types of agents in the simulation model: customer and supplier agents. Here customers are the end users of the products such as laptops, desktops, and printers. Customer agents are divided into three groups according to their shopping preferences:

- customers who buy the product provided by the most reliable original equipment manufacturers (OEMs) in their area of search

- customers who shop according to the popularity of the product manufacturers in their area of search

- customers who buy the product offered at the lowest market price in their area of search.

Customer agents use a modified particle swarm optimisation (PSO) algorithm of Stonedahl and Wilensky (2008) to search through the enterprise ecosystem and find their preferred main supplier. PSO is a search technique in the field of machine learning. In PSO optimisation technique, the main goal is to find values of $x$ and $y$, such that a fitness 
function $f(x, y)$ is maximised. This fitness function determines how good the current position in space is for each customer.

PSO algorithm used in the multi-agent CMEE simulation model can be summarised as follows: Initially customers are placed in the search space randomly. Each customer agent has a position $\left(x_{\mathrm{cor}}, y_{\mathrm{cor}}\right)$ in the search space and a velocity $\left(v_{x}, v_{y}\right)$ with which it moves through that space. Customer agents have a certain amount of inertia, which keeps them moving in the current direction, unless otherwise disturbed. They also have acceleration (rate of change in velocity), which depends on each customer's personal knowledge and population knowledge. As customer agents move farther away from the 'best' locations, the force of attraction grows stronger. There is also a random factor which determines the force with which the customer agents are pulled toward each of the different locations other than the 'best' location.

Supplier agents are divided into three specific groups: Tier 0 (equipment manufacturers), Tier 1 (module or component suppliers) and Tier 2 (raw material suppliers) according to a hierarchical structure of who supplies who. Tier 0 suppliers are the primes or OEMs; they sell products to customers. Tier 1 suppliers provide models and components to Tier 0 suppliers. Tier 2 suppliers provide raw materials to Tier 1 suppliers. All supplier agents share specific common attributes, including the inventory, demand, product price, production rate, budget, energy, and fitness value.

In this list, energy refers to a measure of survival. Each time an order is received and a product is sold, the energy of the supplier which sells the product increases. Each supplier also has a metabolism-rate function. According to this function, at the end of each iteration the energy of the suppliers decreases by a certain amount.

Suppliers have fitness values associated with them. In the case of main suppliers (Tier 0), customers try to find the main supplier with the best global fitness or best local fitness according to their shopping preferences. Therefore the formula for the global fitness value is the total of the three local fitness values.

- fitness-reliability: each supplier has a fitness value associated with its reliability

- fitness-popularity: each supplier has a fitness value associated with its popularity

- fitness-bestprice: each supplier has a fitness value associated with its product price.

Also each supplier agent has environmental fitness threshold values. A list of those values and their role is listed in Table 1.

Table 1 Environmental fitness threshold values and their roles

\begin{tabular}{ll}
\hline Environmental fitness threshold value & Role \\
\hline Energy fitness threshold value & If less than zero, supplier agent dies \\
Budget fitness threshold value & If less than zero, supplier agent dies \\
Supply fitness threshold value & If less than a set value, supplier agent dies \\
Inventory fitness threshold value & If less than a set value, supplier agent dies \\
\hline
\end{tabular}

Supplier agents keep track of the technological changes in the market. They use the concept of adaptation from biological ecosystems. A supplier company might choose to adapt to changes in technologies, become resistant to changes, or stay neutral to changes. During a simulation run suppliers might be in any of the three different states: 
- adaptive state: suppliers track technological changes and adopt them in their manufacturing operations

- resistant state: suppliers as their strategy resist technological changes; and

- neutral state: suppliers track technological changes and they decide to be either in adaptive state or resistant state with equal probability.

Supplier agents also use the concept of cooperation from evolutionary biology. Within CMEE, supplier agents compete for CMEE resources. Supplier agents that are more successful in competition grow faster and open new branches in new locations (reproduce). In the model, two kinds of competition - greedy competition and cooperative competition - are implemented. According to their predefined strategies, each supplier might either try to align with other companies in the system by changing its product price closer to market average; or if the company is not interested in aligning with other companies in the market and prefers to compete greedily, it reduces its product price below market average to sell more products. These two different strategies are examined when supplier agents compete against each other within the CMEE that evolves over time.

The agents maintain vertical and horizontal interactions in the simulation. The horizontal interactions are as follows:

- Customer to customer

- Tier 0 to Tier 0

- Tier 1 to Tier 1

- $\quad$ Tier 2 to Tier 2.

The vertical interactions are between

- Customer and Tier 0

- $\quad$ Tier 0 and Tier 1

- Tier 1 and Tier 2.

In order to secure their positions, supplier agents in different tiers keep track of the number of supplier neighbours (neighbours are agents that are connected through information and collaboration links) with which the supplier agents interact vertically and horizontally. If the number of their neighbours is below a certain threshold, suppliers immediately look for new connections and collaborations. In this process, suppliers drop their weakly connected supplier neighbours and try to link with stronger collaborators. Here suppliers use the revenue of each company as the selection criterion to mark it as a weak or strong collaborator.

In the simulation model, customer agents have a global view which requires the knowledge of states and actions of other agents. Therefore customer agents are aware of brand preferences and favourite products of other customer agents. This is a realistic assumption considering that customers in today's world have a broader information base through social networks such as television advertisements and social networking services. 
Unlike customer agents, supplier agents only have a local view, which means they have either partial or no information about the state, actions, current decisions, future plans and past performance of other supplier agents. Therefore, a supplier agent's state in the ecosystem is affected by its neighbour supplier agent's decisions. It decides its current and future actions according to its local neighbours (first degree link neighbours) and market averages. As a result of these local interactions, the ecosystem evolves, changes, and introduces unexpected vulnerabilities into the system. In a collaborative supply chain, a centralised supplier might have global knowledge, but in this research the supply network evolves in time and it is different from a centralised structure.

\section{Analysis}

After verification and validation of the agent-based simulation model of CMEE, we ran the model to analyse the triple-A virtual CMEE. We performed 1000 simulation runs and recorded supplier and customer agent attributes and environmental parameters in the system. In each epoch of 1000 simulation runs, agents execute a four-step process:

1 The customer places an order with the Tier 0 supplier (OEMs) which has the best global fitness or best local fitness in the customer's area of search.

2 The Tier 0 supplier fulfils the order immediately by drawing products from its inventory if there is enough stock. If the main supplier runs out of stock, it may reject the customer order if its energy level is below a certain threshold, or put the order in queue if it has sufficient energy level.

3 The Tier 0 supplier receives a shipment from a Tier 1 supplier in response to previous orders. The Tier 0 supplier then decides on how much to order next from the Tier 1 supplier based on an 'ordering rule'. The ordering decision is based in part on future demand. The main supplier estimates future customer demand using a 'demand forecasting' rule. The main supplier then orders items from the Tier 1 to cover expected demand and any shortages relative to explicit inventory or pipeline goals.

4 Similarly, each Tier 1 supplier forecasts future demand from Tier 0 suppliers (OEMs), decides on how much to produce and acquire from the raw material (Tier 2) suppliers, and accordingly receives a shipment from a raw material (Tier 2) supplier.

As a result of this process and agent interactions, CMEE acquires certain resiliency trends. We study the relation between the initial number of adaptive suppliers and the number of different types of suppliers (adaptive, resistant, and neutral) that survive at the end of a simulation run. Further, we study the competitive behaviour of the suppliers, and observe their resiliency trends. The performance measures that we study in this simulation are as follows:

- competitive behaviour of the suppliers

- adaptive behaviour of the suppliers. 


\section{Results}

At the end of each simulation run we record the counts of adaptive, resistant, and neutral supplier agents that survived. Figure 1 shows how the numbers of adaptive, neutral and resistant suppliers typically change over time in a simulation run. We observe whether the market is adopting certain resiliency behaviour and if so how this resiliency trend is affecting the enterprise survival. We used the confidence interval on mean number of adaptive, neutral and resistant suppliers. We performed one way ANOVA to investigate whether the mean number of adaptive, neutral and resistant suppliers at the end of a simulation differs for different initial number of adaptive suppliers.

The agent-based simulation is initialised with a total number of 20 suppliers (adaptive, neutral and resistant supplier all together) in the network. Different simulation model scenarios (treatments) are created by setting the initial number of adaptive suppliers to $4,5,6,7,8,9$, or 10 . Accordingly the treatments of the design experiments are referred to as design 4 , design $5, \ldots$, design 10 respectively. For each of the seven designs the average number of adaptive suppliers, average number of neutral suppliers, and average number of resistant suppliers are monitored to study resiliency trends of CMEE.

Figure 2 gives the $99 \%$ confidence interval for the average number of adaptive, neutral and resistant suppliers for different initial number of adaptive suppliers. It can be clearly seen that the number of adaptive suppliers at the end of each simulation run is more than the number of neutral and resistant suppliers in the market. It indicates that enterprises, which adjust their goals and infrastructure quickly in response to the changes in the customers, suppliers, and competitors, survive longer in the CMEE. Surprisingly, the results also point out an interesting observation: the resistant suppliers exhibit better survival ability than neutral suppliers. This interesting survival behaviour can be attributed to the fact that the transition period, when new technologies in the market are being adopted, is a risky period for an enterprise. During the transition period, due to conflicting goals and difficulties in changing infrastructure, enterprises may become vulnerable and fail to survive in the CMEE unless the adaptive behaviour continues on on-going basis. The resistant suppliers, by avoiding risky technologies altogether, stay safer than neutral suppliers.

Next, we performed balanced one-way ANOVA for comparing the means of average number of adaptive suppliers, neutral suppliers, and resistant suppliers for different initial number of adaptive suppliers. Here, each different initial number of adaptive suppliers represents an independent sample containing mutually independent observations. In this research number of treatments is $a=7$ and the number of replications is $n=1000$. The $p$ value is calculated under the null hypothesis that all samples are drawn from populations with the same mean. Therefore we accept null hypothesis if $p=$ probability $\left[F_{a-1, a(n-1)}>F_{0}\right]$ is greater than a preselected signification level $\alpha$. Here $F_{a-1, a(n-1)}$ and $F_{0}$ are the percentage points of $F$ distribution read from $F$-Distribution table and ANOVA table respectively. We used a common significance level of $\alpha=0.05$, i.e., we conclude that the null hypothesis is not true if $p>0.05$. 
Figure 1 Trends in the survival of neutral, adaptive and resistant suppliers in a simulation run (see online version for colours)

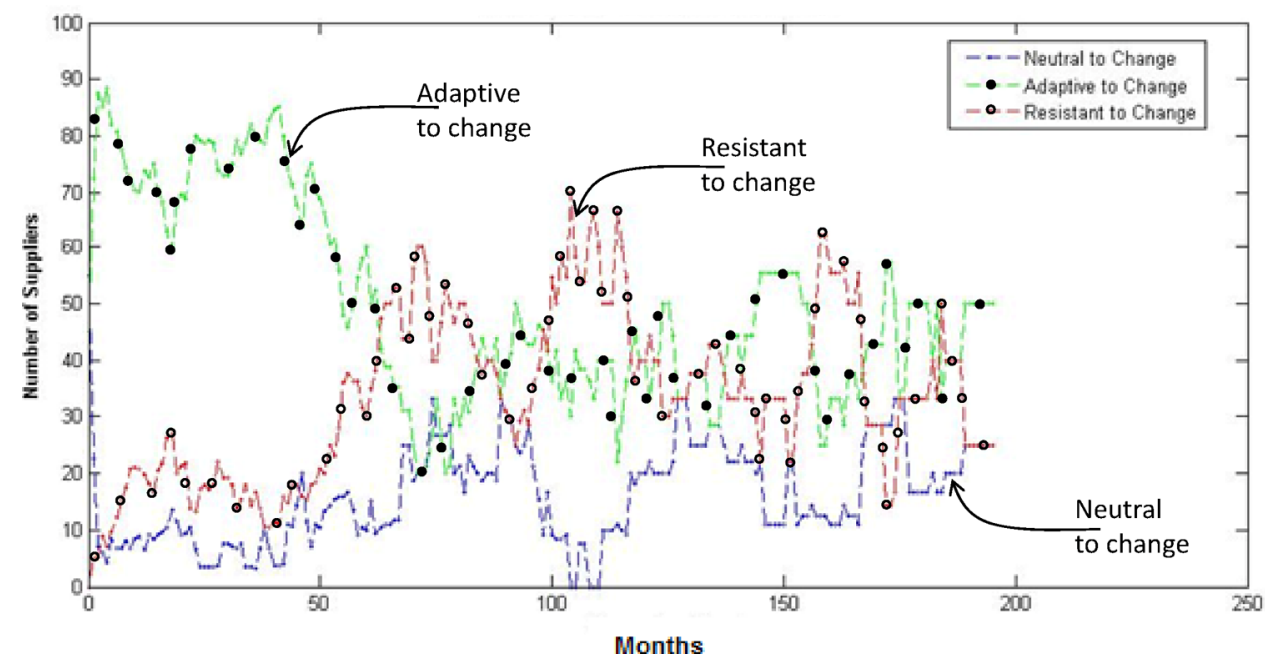

Figure 2 Confidence interval (CI) on the mean of number of neutral, adaptive and resistant suppliers that survived at the end of a simulation run (see online version for colours)

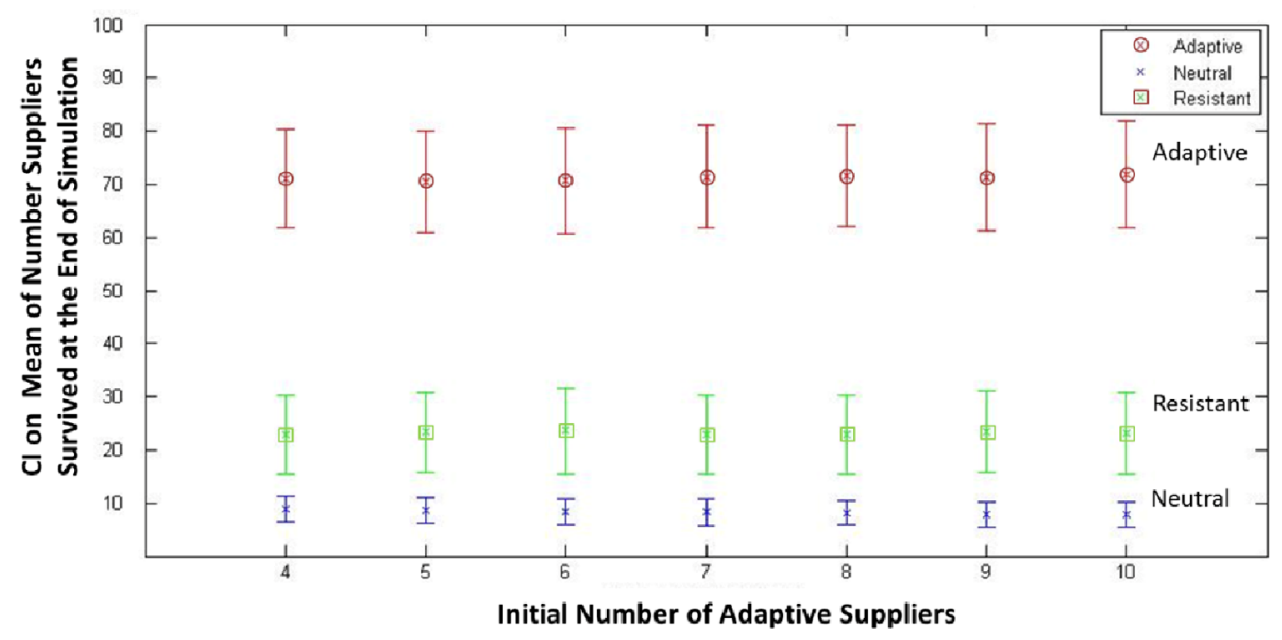

The box plots of these comparisons for adaptive, neutral and resistant suppliers are presented in Figures 3-5, respectively. The box plots mirror the size of the $F$-statistic and the $p$ value. Large differences in the centre lines of the boxes correspond to large values of $F$ and correspondingly small values of $p$.

The result of ANOVA analyses of adaptive and resistant suppliers suggest that the confidence intervals for multiple comparisons all lie above zero $\left(p_{\text {Adaptive }}=0.0359<0.05\right.$ and $p_{\text {Resistant }} \cong 0.00<0.05$ ). Therefore, the null hypothesis is accepted; there is no difference between the means of the number of adaptive suppliers that survived at the end of the simulation runs even though the initial number of adaptive suppliers is different in each of the seven cases. Similar result is observed for the number of resistant suppliers 
that survived at the end of simulation runs. In contrast, ANOVA output for the number of neutral suppliers provides statistically significant evidence that the means of number of neutral suppliers are unequal $\left(p_{\text {Neutral }}=0.2875>0.05\right)$ for different initial number of adaptive suppliers. Therefore, we performed a multiple comparison test to determine where those differences lie.

Figure 3 One way ANOVA for comparing the means of number of adaptive suppliers for different initial number of adaptive suppliers (see online version for colours)

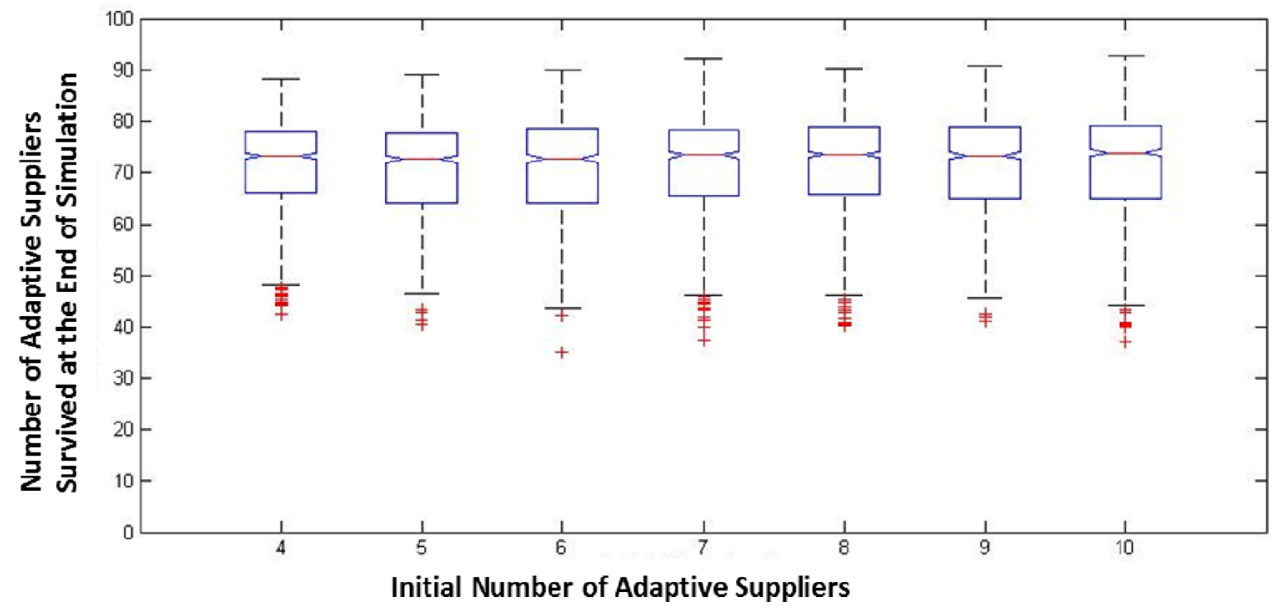

Figure 4 One way ANOVA for comparing the means of number of neutral suppliers for different initial number of adaptive suppliers (see online version for colours)

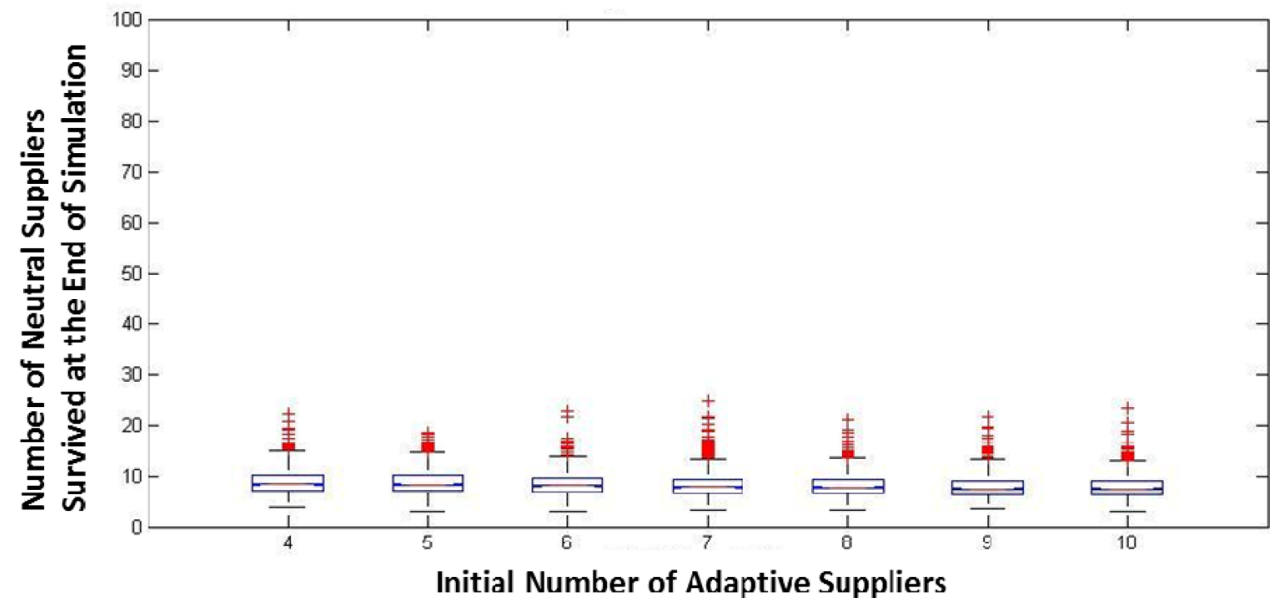

According to the multiple comparisons method results, shown in Table 2 and Figure 6, confidence intervals for some comparisons of means of number of neutral agents does not include zero. This infers that there is statistically significant difference among seven neutral supplier designs. 
Figure 5 One way ANOVA for comparing the means of number of resistant suppliers for different initial number of adaptive suppliers (see online version for colours)

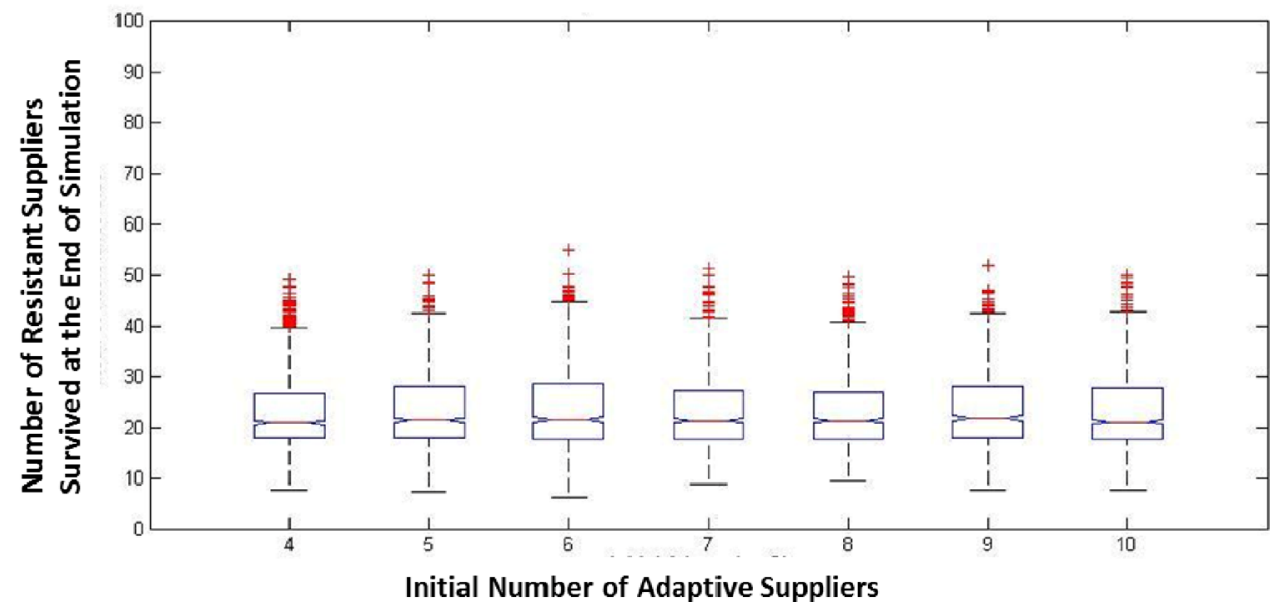

The confidence intervals of pairwise differences $\mu_{4}-\mu_{6}, \mu_{4}-\mu_{7}, \mu_{4}-\mu_{8}, \mu_{4}-\mu_{9}$, $\mu_{4}-\mu_{10}, \mu_{5}-\mu_{6}, \mu_{5}-\mu_{7}, \mu_{5}-\mu_{8}, \mu_{5}-\mu_{9}$, and $\mu_{5}-\mu_{10}$ lie completely above zero ( $\mu_{i}$ represent the mean number of neutral suppliers for design $i$ ). This indicates that design treatments with initial number of adaptive suppliers equal to $6,7,8,9$ and 10 are significantly different from design treatments with initial number of adaptive suppliers equal to 4 and 5 . There is no statistically significant difference among designs 4 and 5.

Similarly, the confidence intervals for $\mu_{6}-\mu_{9}, \mu_{6}-\mu_{10}, \mu_{7}-\mu_{9}, \mu_{7}-\mu_{10}$ and $\mu_{8}-\mu_{10}$ also lie completely above zero. This reflects that designs 9 and 10 are significantly different from design 6 and 7. Also, design 10 is significantly different from all other designs except design 9.

However, confidence intervals for $\mu_{6}-\mu_{7}, \mu_{6}-\mu_{8}, \mu_{7}-\mu_{8}, \mu_{8}-\mu_{9}, \mu_{9}-\mu_{10}$ contain zero. From this we can infer that there is no statistically significant difference among these pairs of designs. In other words, there is no statistically significant change in average number of neutral agents, when the initial number of adaptive agents is increased from 6 to 7,6 to 8,7 to 8,8 to 9 and 9 to 10 .

We can conclude from these results that the simulation model produces no statistically significant difference in the means of number of adaptive and resistant suppliers. However, it produces statistically significant difference in the means of number neutral suppliers. Therefore, the simulation model produces statistically significant results for the adaptive trend of adaptive and resistant suppliers. Though, the simulation model does not provide clear results for the adaptive trend of neutral suppliers.

Two kinds of competition methods are implemented in the simulation model. In one competition method suppliers are greedy and in the other suppliers are cooperative. These two different strategies are examined and the results are presented in Figures 7 and 8 . The number of cooperative and greedy suppliers is referred as cooperation size in Figure 8. 
Resiliency characteristics of a competitive and collaborative complex

Table 2 Multiple pairwise comparisons of neutral suppliers performed at the 0.05 level

\begin{tabular}{lccll}
\hline Sample 1 & Sample 2 & Lower limit & Mean & Upper limit \\
\hline 4 & 5 & -0.1838 & 0.127 & 0.4377 \\
4 & 6 & 0.1362 & 0.4469 & 0.7577 \\
4 & 7 & 0.2104 & 0.5212 & 0.8319 \\
4 & 8 & 0.3614 & 0.6722 & 0.9829 \\
4 & 9 & 0.5847 & 0.8954 & 1.2061 \\
4 & 10 & 0.7033 & 1.0141 & 1.3248 \\
5 & 6 & 0.0092 & 0.32 & 0.6307 \\
5 & 7 & 0.0835 & 0.3942 & 0.705 \\
5 & 8 & 0.2345 & 0.5452 & 0.8559 \\
5 & 9 & 0.4577 & 0.7685 & 1.0792 \\
5 & 10 & 0.5764 & 0.8871 & 1.1978 \\
6 & 7 & -0.2365 & 0.0743 & 0.385 \\
6 & 8 & -0.0855 & 0.2252 & 0.536 \\
6 & 9 & 0.1377 & 0.4485 & 0.7592 \\
6 & 10 & 0.2564 & 0.5671 & 0.8779 \\
7 & 8 & -0.1598 & 0.151 & 0.4617 \\
7 & 9 & 0.0635 & 0.3742 & 0.685 \\
7 & 10 & 0.1821 & 0.4929 & 0.8036 \\
8 & 9 & -0.0875 & 0.2232 & 0.534 \\
8 & 10 & 0.0312 & 0.3419 & 0.6526 \\
9 & 10 & -0.1921 & 0.1186 & 0.4294 \\
\hline & & & &
\end{tabular}

Figure 6 Multiple pairwise comparisons of neutral suppliers for different initial number of adaptive suppliers (see online version for colours)

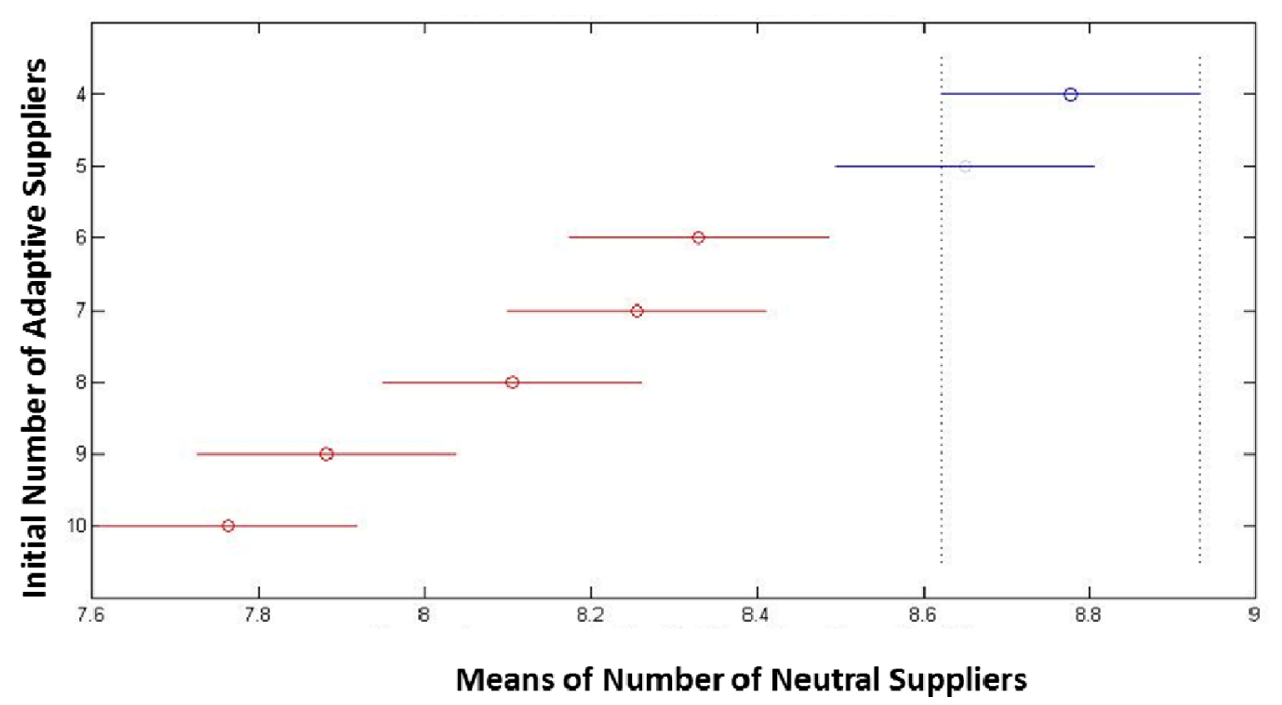


Figure 7 The trends of number of cooperative and greedy suppliers in a simulation run (see online version for colours)

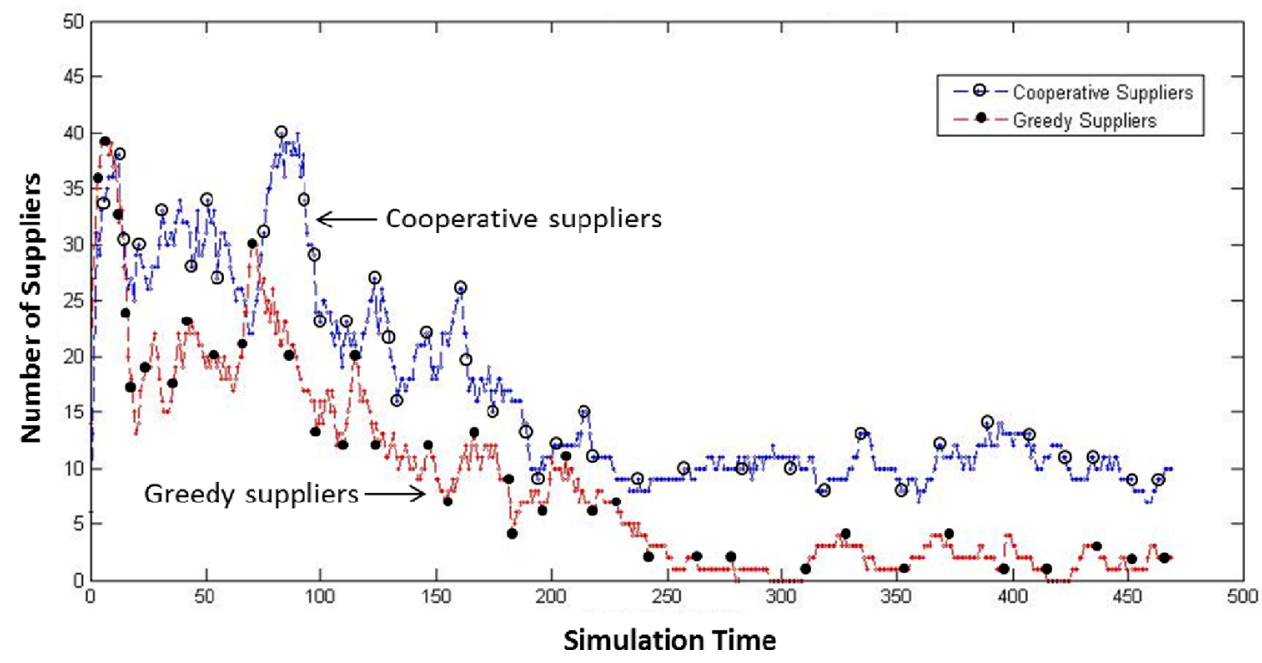

Figure 7 shows how the numbers of cooperative and greedy suppliers change while competing against each other within the CMEE that evolves over time in one simulation run. According to this run, the cooperative suppliers are more successful in surviving than the greedy suppliers in the CMEE. In order to obtain statistically accurate results, we took a sample of 1000 runs to compute confidence intervals on mean number of cooperative and mean number of greedy suppliers. The results shed a light on whether the CMEE is adopting resiliency behaviour under cooperative and greedy competition.

Figure 8 gives the $99 \%$ confidence interval for the average number of cooperative and greedy suppliers. It can be clearly seen that the number of cooperative suppliers is larger than the number of greedy suppliers in the market at the end of each simulation run.

Figure 8 Confidence interval (CI) on mean number of cooperative and greedy suppliers survived at the end of the simulation (see online version for colours)

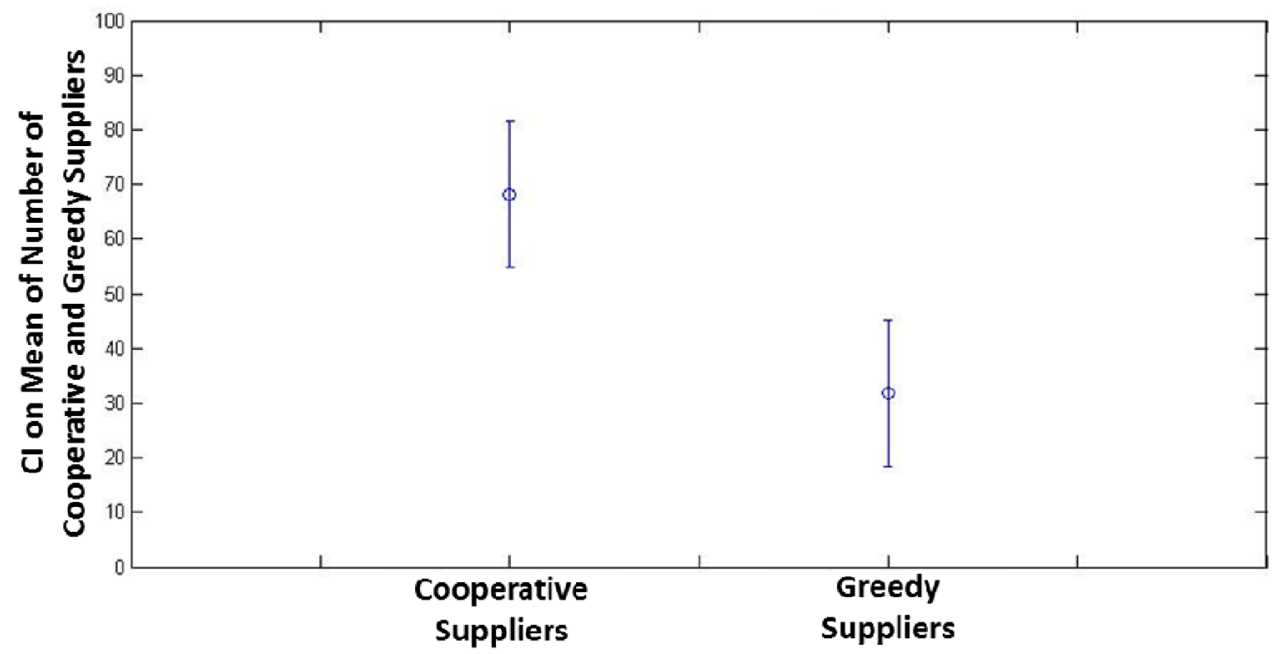


This result proves that suppliers, which adopt the cooperative behaviour, benefit from increased collaboration and information flow with their neighbours and gain advantage over their greedy competitors. The fitness levels of cooperative suppliers increase and as a result they survive longer in the CMEE.

\section{Discussion and conclusion}

In this paper, we investigated adaptation and collaboration mechanisms in CMEE to better understand their possible evolutionary paths. Specifically, we have accomplished the following:

- demonstrated the use of agent-based simulation method to study the evolution and self-organisation of CMEE

- constructed a comprehensive and realistic model of CMEE that provides insights into the behaviour of enterprises that are highly dynamic, scalable, aligned, agile and adaptive

- conducted a comprehensive study on the effect of uncertain and rapidly changing business environments in the CMEE

- performed statistical analysis on the model outputs.

We developed a structured framework for designing triple-A CMEEs. In order to simulate various facets of CMEE, we constructed an agent-based simulation model that contributes to the understanding and implementation of agile, adaptive and aligned computer manufacturing enterprises.

We presented an in-depth analysis of resiliency of computer manufacturing enterprises in CMEE. The results showed that adaptive enterprises, which adjust goals and infrastructure quickly according to changes induced by customers, suppliers, and competitors, survive longer in the CMEE compared to the resistant enterprises. Surprisingly, the resistant suppliers show better resiliency than neutral suppliers. This is attributed to the fact that resistant suppliers, by avoiding risky technologies altogether, stay safer than neutral suppliers which adopt technology changes once in a while but do not follow through like adaptive suppliers.

According to the results, it was shown that enterprises, which adopt the cooperative behaviour benefit from increased collaboration and information flow with their neighbours and gain advantage over their greedy competitors. Their fitness levels increase and as a result they survive longer in the CMEE.

Companies can use the outcomes of this research to build agile, robust, and adaptive enterprises that anticipate, transform, and thrive in harsh business environment conditions. This research focuses primarily on desktop and laptop computer related companies as test beds to demonstrate the approach; however the approaches and methodologies developed herein are broadly applicable to industries such as consumer electronics and automobiles sectors that operate in rapidly changing business environment. 


\section{References}

Amini, M., Wakolbinger, T., Racer, M. and Nejad, M.G. (2012) 'Alternative supply chain production-sales policies for new product diffusion: an agent-based modeling and simulation approach', European Journal of Operational Research, Vol. 216, No. 2, pp.301-311.

Baldwin, J.S., Allen, P.M. and Ridgway, K. (2010) 'An evolutionary complex systems decisionsupport tool for the management of operations', International Journal of Operations \& Production Management, Vol. 30, Nos. 7-8, pp.700-720.

Barlas, Y. and Gunduz, B. (2011) 'Demand forecasting and sharing strategies to reduce fluctuations and the bullwhip effect in supply chains', Journal of the Operational Research Society, Vol. 62, No. 3, pp.458-473.

Chan, H.K. and Chan, F.T.S. (2010) 'Comparative study of adaptability and flexibility in distributed manufacturing supply chains', Decision Support Systems, Vol. 48, No. 2, pp.331-341.

Choi, T.Y. and Hong, Y. (2002) 'Unveiling the structure of supply networks: case studies in Honda, Acura, and DaimlerChrysler', Journal of Operations Management, Vol. 20, No. 5 , pp.469-493.

Datta, P.P. and Christopher, M.G. (2011) 'Information sharing and coordination mechanisms for managing uncertainty in supply chains: a simulation study', International Journal of Production Research, Vol. 49, No. 3, pp.765-803.

Economist, E.I.U.L. (2009) 'Organisational agility: How business can survive and thrive in turbulent times', The Economist, pp.1-27, http://www.emc.com/collateral/leadership/ organisational-agility-230309.pdf (Last accessed on 24 July, 2014).

ElMaraghy, H.A. (2006) 'Flexible and reconfigurable manufacturing systems paradigms', International Journal of Flexible Manufacturing Systems, Vol. 17, No. 4, pp.261-276.

Harland, C.M., Lamming, R.C., Zheng, J. and Johnsen, T.E. (2001) 'A taxonomyof supply networks', Journal of Supply Chain Management, Vol. 37, No. 4, pp.21-27.

Heese, H.S. (2012) 'Retail strategies for extended warranty sales and impact on manufacturer base warranties', Decision Sciences, Vol. 43, No. 2, pp.341-367.

Ito, K. and Gunji, Y-P. (1994) 'Self-organisation of living systems towards criticality at the edge of chaos', Biosystems, Vol. 33, No. 1, pp.17-24.

Jiang, G., Hu, B. and Wang, Y. (2010) 'Agent-based simulation of competitive and collaborative mechanisms for mobile service chains', Information Sciences, Vol. 180, No. 2, pp.225-240.

Kaihara, T. (2003) 'Multi-agent based supply chain modelling with dynamic environment', International Journal of Production Economics, Vol. 85, No. 2, pp.263-269.

Kelton, W.D., Sadowski, R.P. and Sadowski, D.A. (1998) Simulation with ARENA, McGraw Hill, New York.

Kim, W-S. (2009) 'Effects of a trust mechanism on complex adaptive supply networks: an agentbased social simulation study', Journal of Artificial Societies and Social Simulation, Vol. 12, No. 3, p.4.

Koren, Y., Heisel, U., Jovane, F., Moriwaki, T., Pritschow, G., Ulsoy, G. and Van Brussel, H. (1999) 'Reconfigurable manufacturing systems', CIRP Annals - Manufacturing Technology, Vol. 48, No. 2, pp.527-540.

Krause, D.R., Scannell, T.V. and Calantone, R.J. (2000) 'A structural analysis of the effectiveness of buying firms' strategies to improve supplier performance', Decision Sciences, Vol. 31, No. 1, pp.33-55.

Law, A.M. (2006) Simulation Modeling and Analysis, 4th ed., McGraw Hill Science/ Engineering/Math.

Lee, H.L. (2004) 'The triple-A supply chain', Harvard Business Review, Vol. 82, No. 10, pp.102-112, 157. 
Li, G., Ji, P., Sun, L.Y. and Lee, W.B. (2009) 'Modeling and simulation of supply network evolution based on complex adaptive system and fitness landscape', Computers \& Industrial Engineering, Vol. 56, No. 3, pp.839-853.

Mahajan, J., Radas, S. and Vakharia, A.J. (2002) 'Channel strategies and stocking policies in uncapacitated and capacitated supply chains', Decision Sciences, Vol. 33, No. 2, pp.191-222.

Mizgier, K.J., Wagner, S.M. and Holyst, J.A. (2012) 'Modeling defaults of companies in multistage supply chain networks', International Journal of Production Economics, Vol. 135, No. 1, pp.14-23.

Monteiro, T., Portmann, M-C. and Khouider, S. (2010) 'Evaluation model framework based on simulation for enterprise network negotiation mechanisms', Production Planning \& Control, Vol. 21, No. 6, pp.581-594.

Nair, A. and Vidal, J.M. (2011) 'Supply network topology and robustness against disruptions - an investigation using multi-agent model', International Journal of Production Research, Vol. 49, No. 5, pp.1391-1404.

Nair, A., Narasimhan, R. and Choi, T.Y. (2009) 'Supply networks as a complex adaptive system: toward simulation-based theory building on evolutionary decision making', Decision Sciences, Vol. 40, No. 4, pp.783-815.

Pascual, M., Roy, M., Guichard, F. and Flierl, G. (2002) 'Cluster size distributions: signatures of self-organization in spatial ecologies', Philosophical transactions of the Royal Society of London. Series B, Biological sciences, Vol. 357, No. 1421, pp.657-666.

Pathak, S.D., Dilts, D.M. and Mahadevan, S. (2009) 'Investigating population and topological evolution in a complex adaptive supply network', Journal of Supply Chain Management, Vol. 45, No. 3, pp.54-67.

Pritsker, A.A.B. and Pegden, C.D. (1984) Introduction to Simulation and SLAM, John Wiley and Sons, New York.

Qi, Y., Boyer, K.K. and Zhao, X. (2009) 'Supply chain strategy, product characteristics, and performance impact: evidence from chinese manufacturers', Decision Sciences, Vol. 40, No. 4, pp.667-695.

Qi, Y., Zhao, X. and Sheu, C. (2011) 'The impact of competitive strategy and supply chain strategy on business performance: the role of environmental uncertainty', Decision Sciences, Vol. 42, No. 2, pp.371-389.

Robinson, E.P. and Satterfield, R.K. (1998) 'Designing distribution systems to support vendor strategies in supply chain management', Decision Sciences, Vol. 29, No. 3, pp.685-706.

Robinson, E.P., Sahin, F. and Gao, L.L. (2005) 'The impact of E-replenishment strategy on maketo-order supply chain performance', Decision Sciences, Vol. 36, No. 1, pp.33-64.

Setchi, R.M. and Lagos, N. (2004) 'Reconfigurability and reconfigurable manufacturing systems state-of-the-art review', 2nd IEEE International Conference on Industrial Informatics, INDIN'04, 2004 2nd IEEE International Conference on Industrial Informatics: Collaborative Automation - One Key for Intelligent Industrial Environments, INDIN'04, Berlin, pp.529-535.

Sneppen, K., Bak, P., Flyvbjerg, H. and Jensen, M.H. (1995) 'Evolution as a self-organized critical phenomenon', Proceedings of the National Academy of Sciences of the United States of America, Vol. 92, No. 11, pp.5209-5213.

Stonedahl, F. and Wilensky, U. (2008) NetLogo Particle Swarm Optimization model. Evanston, IL: Center for Connected Learning and Computer-Based Modeling, Northwestern University, Accessed 7 November, 2012, Available at http://ccl.northwestern.edu/netlogo/models/ ParticleSwarmOptimization.

$\mathrm{Su}, \mathrm{J}$. and Chen, F. (2004) 'Control software for reconfigurable manufacturing systems: state-ofthe-art review and future trends', IIE Annual Conference and Exhibition 2004, IIE Annual Conference and Exhibition 2004, pp.1397-1402.

Tang, Y. and Qiu, R.G. (2004) 'Integrated design approach for virtual production line-based reconfigurable manufacturing systems', International Journal of Production Research, Vol. 42, No. 18, pp.3803-3822. 
Terano, T., Arai, K., Deguchi, H., Kaneda, T., Kita, H. and SpringerLink (Online service) (2005) 'Agent-based simulation: from modeling methodologies to real-world applications', PostProceedings of the Third International Workshop on Agent-Based Approaches in Economic and Social Complex Systems 2004, Springer-Verlag, Tokyo.

Wang, F., Hou, Z-G., Xu, D. and Tan, M. (2005) 'An agent-based holonic architecture for reconfigurable manufacturing systems', Advances in Natural Computation: First International Conference, ICNC 2005, pp.622-627.

Wang, X.H., Wong, T.N. and Wang, G. (2011) 'Knowledge representation for multi-agent negotiations in virtual enterprises', International Journal of Production Research, Vol. 49, No. 14, pp.4275-4297.

Wilensky, U. (1999) NetLogo. Center for Connected Learning and Computer-Based Modeling, Northwestern University, Evanston, IL.

Zhang, J., Chan, F.T.S., Li, P., Lau, H.C.W., Ip, R.W.L. and Samaranayak, P. (2002) 'Investigation of the reconfigurable control system for an agile manufacturing cell', International Journal of Production Research, Vol. 40, No. 15, pp.3709-3723.

Zhang, Y., Bhattacharyya, S. and Li, X. (2010) 'From choice of procurement strategy to supply network configuration: an evolutionary approach', International Journal of Information Technology \& Decision Making, Vol. 9, No. 1, pp.145-173. 